\title{
An improved droop control strategy in islanded micro-grid Ran $\mathrm{Tao}^{1}$, Rong $\mathrm{Ju}^{2}$
}

School of Electrical and Automation Engineering, Nanjing Normal University, Nanjing 210000, China

\section{4@qq.com}

Keywords: Micro grid; droop control; feeder impedance; virtual impedance

\begin{abstract}
The traditional droop control has the advantages of low cost, easy to expand, easy to proportional load sharing and so on. But the micro-grid line impedance is resistive, which makes the output power coupling each other .The virtual impedance control strategy can help micro-grid converter to realize active power and reactive power decoupling but the large virtual impedance value will lead to the voltage drop of the system. This paper presents an improved droop control strategy with voltage feedback, which is a method to solve the problem of pressure drop after the introduction of virtual impedance. Simulation results are provided to verify the analysis and design.
\end{abstract}

\section{Introduction}

At present, the research of micro grid control technology is still in its infancy, and the research focus is in the field of distributed generation and energy storage.However, the distributed energy resources in the micro grid need to be connected to the grid through the inverter, so the research on the control strategy of the inverter can effectively reduce the power quality of the system[1-5].Reference [6] using a new reference voltage formed by the difference between the reference voltage and the virtual voltage helped micro-grid converter to realize active power and reactive power decoupling but lead to the voltage drop of the system.Reference [7] the control strategy of autonomous micro grid based on coordinate rotational virtual impedance is proposed to handle this problem.But the control process is too complicated, it is difficult to achieve in practical engineering application.

This paper describes the relationship between the virtual impedance and bus voltage in droop control strategy. On the basis of this, the voltage feedback is introduced. When the system load is abrupt, the control strategy can maintain the stability of the output voltage of the inverter.

\section{The micro grid structure}

Fig. 1 shows a schematic diagram of the micro grid structure, distributed resources is connected in parallel with hybrid energy storage system via DC bus,constitute power adjustable distributed resources.But the low voltage micro-grid line impedance is resistive, which makes the output power coupling each other.

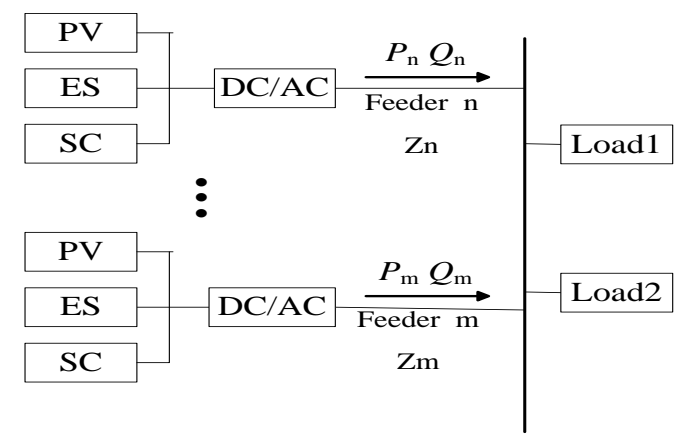

Fig.1The micro grid structure 


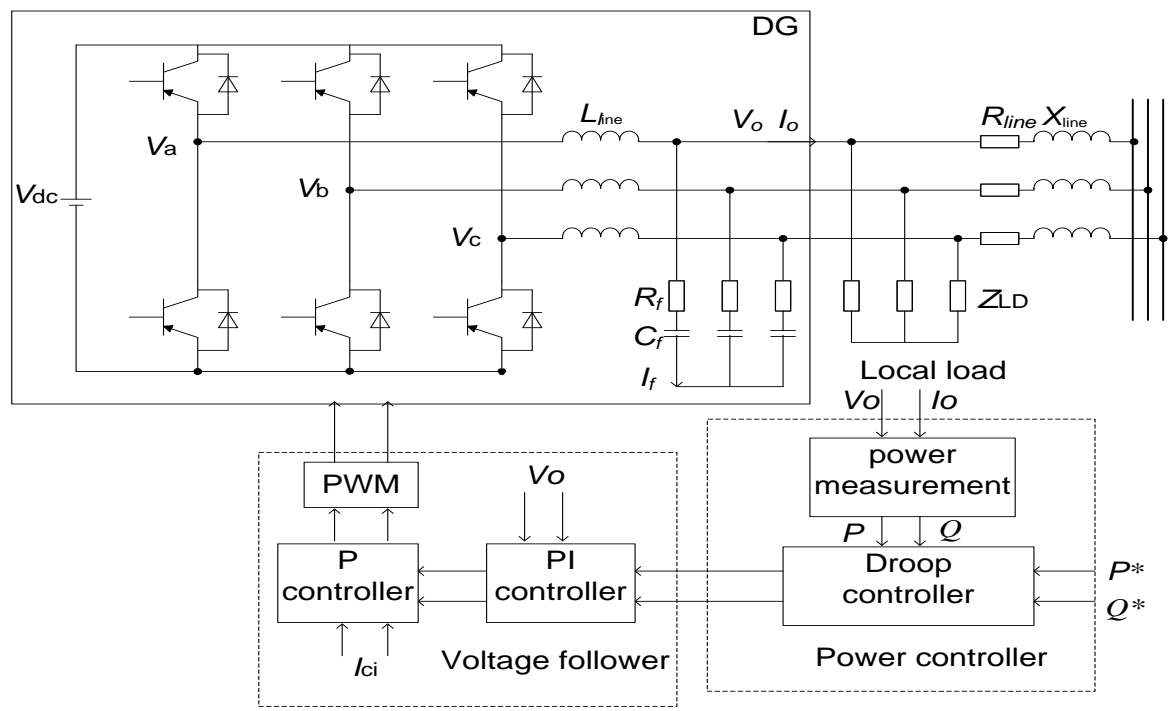

Fig.2 Droop control strategy principle diagram

\section{Droop control strategy based on virtual impedance}

\section{Effect of line impedance on droop control}

In the micro grid operation, there are usually many inverters in parallel operation.Fig.2 shows the 2 inverters parallel operation.

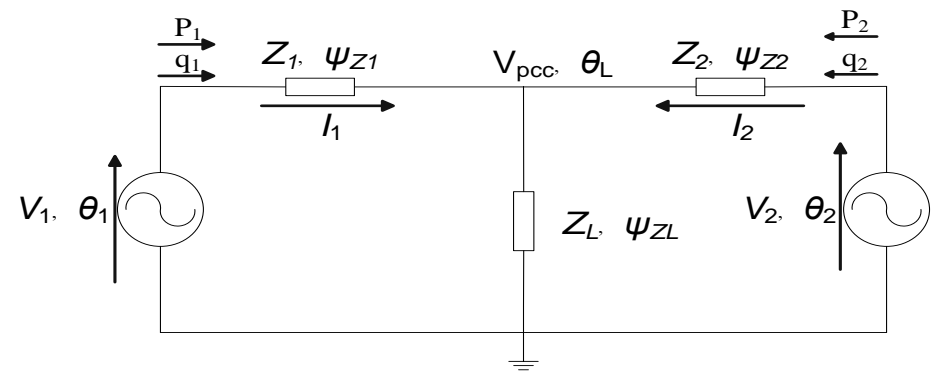

Fig.3 The 2 inverters parallel operation

$\mathrm{S}_{\mathrm{i}}=P_{\mathrm{i}}+\mathrm{j} Q_{\mathrm{i}}$

$$
=\left(\frac{V_{\mathrm{i}}^{2}}{Z_{\mathrm{i}}} \cos \psi_{\mathrm{zi}}-\frac{V_{\mathrm{i}} V_{P C C}}{Z_{\mathrm{i}}} \cos \left(\theta_{\mathrm{iL}}+\psi_{\mathrm{zi}}\right)\right)+\mathrm{j}\left(\frac{V_{\mathrm{i}}^{2}}{Z_{\mathrm{i}}} \sin \psi_{\mathrm{zi}}-\frac{V_{\mathrm{i}} V_{P C C}}{Z_{\mathrm{i}}} \sin \left(\theta_{\mathrm{iL}}+\psi_{\mathrm{zi}}\right)\right)
$$

From the formula (1) can be known, When the impedance of the circuit is inductive, $\psi_{\mathrm{i}}=90^{\circ}$.

Considering that the angle between the output voltage vector of inverter and the PCC voltage vector is very small, the output of the inverter can be obtained:

$$
\left\{\begin{array}{l}
P_{\mathrm{i}}=\frac{V_{\mathrm{i}} V_{P C C}}{Z_{i}} \sin \theta_{\mathrm{iL}} \approx \frac{V_{i} V_{P C C}}{Z_{i}} \theta_{\mathrm{iL}} \\
Q_{i}=\frac{V_{i}}{Z_{i}}\left(V_{i}-V_{P C C} \cos \theta_{\mathrm{iL}}\right) \approx \frac{V_{i}}{Z_{i}}\left(V_{i}-V_{P C C}\right)
\end{array}\right.
$$

When the inverter voltage vector amplitude is constant,the active power is affected by the phase angle difference of two voltage vectors. When the inverter voltage vector angle is constant, the output of reactive power is affected by amplitude difference of the two voltage vectors amplitude difference .

When the impedance of the circuit is resistance, $\psi_{\mathrm{i}}=0^{\circ}$, the output of the inverter can be obtained: 


$$
\left\{\begin{array}{l}
P_{\mathrm{i}}=\frac{V_{i}}{Z_{i}}\left(V_{i} \cos \theta_{\mathrm{iL}}-V_{P C C}\right) \approx \frac{V_{i}}{Z_{i}}\left(V_{i}-V_{P C C}\right) \\
Q_{i}=-\frac{V_{\mathrm{i}} V_{P C C}}{Z_{i}} \sin \theta_{\mathrm{iL}} \approx-\frac{V_{i} V_{P C C}}{Z_{i}} \theta_{\mathrm{iL}}
\end{array}\right.
$$

When the inverter voltage vector amplitude is constant,the output of reactive power is affected by amplitude difference of the two voltage vectors amplitude difference. When the inverter voltage vector angle is constant, the active power is affected by the phase angle difference of two voltage vectors.

When the impedance of the circuit is Resistance-Inductance, $0^{\circ}\left\langle\psi_{\mathrm{i}}\left\langle 90^{\circ}\right.\right.$, the output of the inverter can be obtained:

$$
\left\{\begin{array}{l}
P_{i}=\frac{1}{Z_{i}}\left(\left(V_{i}-V_{P C C} \cos \theta_{i L}\right) V_{i} \cos \psi_{Z i}+V_{i} V_{P C C} \sin \theta_{i L} \sin \psi_{Z i}\right) \\
Q_{i}=\frac{1}{Z_{i}}\left(\left(V_{i}-V_{P C C} \cos \theta_{i L}\right) V_{i} \sin \psi_{Z i}-V_{i} V_{P C C} \sin \theta_{i L} \cos \psi_{Z i}\right)
\end{array}\right.
$$

At this time, change the inverter voltage phase angle or amplitude, the inverter output active power and reactive power all under the influence.Active power and reactive power of the inverter is coupling each other .Therefore, the traditional droop control can not achieve good control effect.

\section{Application of virtual impedance in droop control}

The coupling problem of droop control can be solved by using virtual impedance[9-15].The principle of virtual impedance is:Sampling the output current from the micro grid,calculating the expected impedance pressure drop with the product of the expected impedance and the output current, then subtract the desired impedance from the reference voltage and the new voltage is used as an inner control command,when the system is in good tracking of the command voltage, we can be obtained in the original micro power supply to increase the same voltage output as the same as the actual expected.The expected impedance is virtual impedance.

The virtual impedance equivalent process is shown in Fig.4.

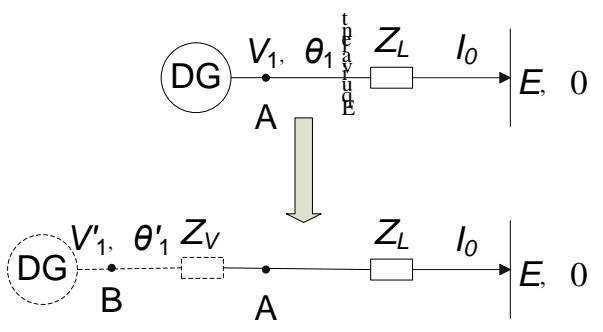

Fig.4 The virtual impedance equivalent process

The output voltage of the inverter after the introduction of the virtual impedance

$$
\mathrm{V}_{1}=\mathrm{V}_{1}^{\prime}-Z_{0} I_{0}
$$

The reference [8] has proved the feasibility of controlling the output power of the inverter by controlling the output voltage of the inverter.The virtual impedance control can help micro-grid converter to realize active power and reactive power decoupling.

\section{An improved droop control strategy}

From the front of the elements when taking the traditional droop control,the bus voltage of the system is reduced when the system load is increased, and the virtual impedance makes pressure drop again.In order to keep the droop control system characteristic and good voltage quality an improved droop control strategy is proposed in this paper.The control diagram is shown in fig. 4 .

After comparing the output voltage of the droop controller with the given voltage,using the integral control and proportional control to form voltage feedback control. 


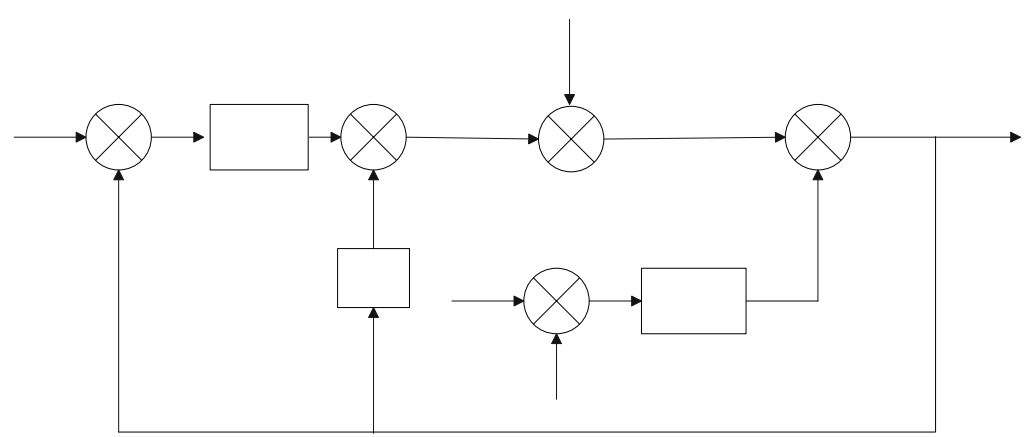

Fig.5 An improved droop control diagram

$$
U_{i}=\frac{\frac{K_{i}}{s} U_{r}+U_{r e f}-n_{i}\left(Q^{*}-Q_{i}\right)}{1+K_{p}+\frac{K_{i}}{s}}
$$

Due to the introduction of voltage feedback,the voltage change caused by load change and virtual impedance is compensated.The bus voltage of the system can be stabilized in the normal range.It overcomes the influence of the droop control coefficient and the virtual impedance on the bus voltage.

\section{Simulation analysis}

Build islanded micro grid simulation model in Matlab/Simulink, validate the control strategy used in this paper.

Distributed resources parameters : $V_{\mathrm{dc}}=800 \mathrm{~V}, P_{\mathrm{n}}=20 \mathrm{~kW}, \mathrm{f}_{\mathrm{n}}=50 \mathrm{~Hz}, U_{0}=311 \mathrm{~V}$ ， $\mathrm{n}=3 \times 10^{-4}, \mathrm{~m}=1 \times 10^{-5}$

Filter parameters: $R_{\mathrm{f}}=0.01 \Omega, \mathrm{L}_{\mathrm{f}}=0.6 \times 10^{-3} \mathrm{H}, \mathrm{C}_{\mathrm{f}}=1.5 \times 10^{-3} \mathrm{~F}$,

Line parameters: $R_{\text {Line }}=0.12 \Omega, \mathrm{L}_{\text {line }}=6.34 \times 10^{-5} \mathrm{H}$

Virtual impedance: $\mathrm{L}_{\mathrm{v}}=0.0012 \mathrm{H}$

Load: $P_{1}=10 \mathrm{~kW} \quad P_{2}=P_{3}=5 \mathrm{~kW}, Q_{1}=Q_{2}=Q_{3}=5 \mathrm{kwar}$

Simulation based on virtual impedance droop control model and improved model.The simulation time is 6 seconds,Start the system with load1,2 seconds input load2,4 seconds input load3.The simulation results are shown in Figure 6 and 7.

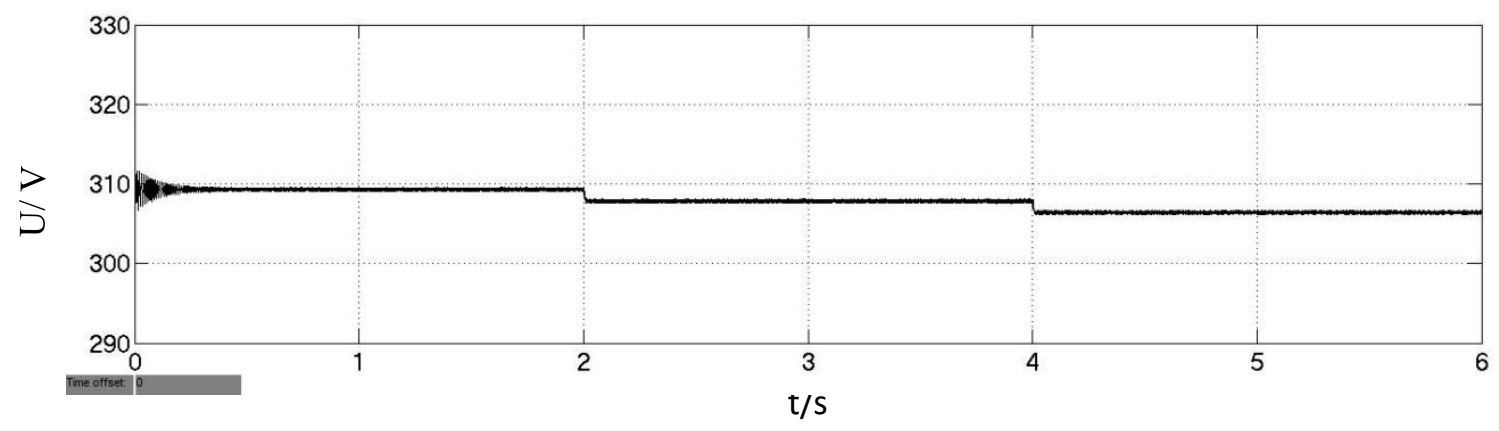

Fig.6 Bus voltage of virtual impedance droop control 


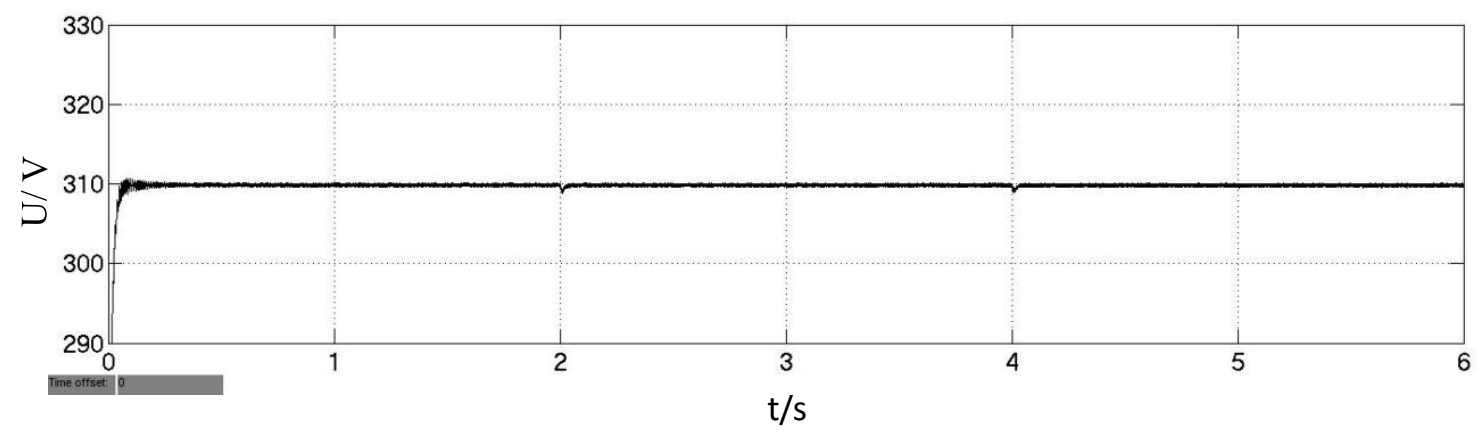

Fig.7 Bus voltage of Improved droop control

From Figure 6, 7 can be known, in 2 seconds and 4 seconds due to loads input,traditional droop control model bus voltage has obvious pressure drop.The improved micro grid model after put into the loads can quickly adjust the bus voltage, so as to achieve the normal working voltage and improve the quality of power .

\section{Conclusions and outlook}

This paper analyzes the reasons of the power coupling of the droop control in the isolated island micro grid and the reason of voltage drop after the virtual impedance is introduced.An improved droop control is presented and Simulation results show the effectiveness of the improved control.But the droop control strategy proposed in this paper can only meet the requirements of micro grid primary adjustment of frequency, and the next step is to study the application of secondary frequency regulation and tertiary FM frequency regulation in micro grid.

\section{References}

[1] C.S.Wang ,Z.Wu , P.Li.Research on Key Technologies of Microgrid, J.Transactions of China Electrotechnical Society,2014,02:1-12.

[2] Q.L.Zhao, X.Q.Guo , W.Y.Wu.Research on Control Strategy for Single-Phase Grid-connected Inverter, J.A Journal of The Chinese Society for Electrical Engineering,2007, 27(16): 60-64.

[3] Y.C.Xue, N.L.Tai,L.Q.Liu,et al.. Co-operation control strategies for islanded microgrids, J..Electric Power,2009,42(7): 36-40.

[4] D.K.Gao, J.G.Jiang, Y.H.Zhang.Design of Micro grid Control Strategy Using Voltage Amplitude and Phase Angle Droop Control, J.Automation of Electric Power Systems,2012,36(5): 29-34.

[5] B.B.Wu, J.H.Su, J.J.Zhang, et al..Control Strategies of Inverter in Micro grid Island Operation, J.PROCEEDINGS OF THE CHINESE SOCIETY OF UNIVERSITIES,2011,23(1):1-5.

[6] T.Y.Ma ,Research on performance optimization control strategy of micro grid in island mode, D.Beijing Jiaotong University, 2014.

[8] J.Z.Cheng,S.S.Li,Z.Z.Wu, et al..Analysis of Power Decoupling Mechanism for Droop Control with Virtual Inductance in a Micro grid, J.Automation of Electric Power Systems,2012,36(7):27-32.

[7] R.Q.Wang ,Y.Cheng ,S.M.Sun;et al..Control and performance analysis of micro grid based on coordinate rotational virtual impedance, J.Power System Protection and Control,2014,06:78-85.

[9] Y.Zhang ,L.Guo ,H.J.Jia.Improved Droop Control Method for Micro grid Based on Additional Damping, J.Automation of Electric Power Systems,2015, 39(18):25 - 30.

[10] Z.C.Yang, K.P.Liu , J.Le ,et al..Design of Fuzzy PID Droop Controllers for Islanded Micro grids, J.Automation of Electric Power Systems,2013,37(12):19-23. 
[11] Y.L.Xie;Z.J.Cheng;Y.D.Li;et al..A droop control strategy for parallel inverters with virtual impedance, J.Advanced Technology of Electrical Engineering and Energy.2016,35(3):22-25.

[12] Liu X ,Wang P M,Loh P C.A hybrid AC/DC micro-grid and its coordination control, J.IEEE Transactions on Smart Grid,2011,2(2):278-286.

[13] W.Bao, X.H.Hu, G.H.Li, et al..An improved droop control strategy based on virtual impedance in islanded micro-grid, J.Power System Protection and Control.2013,41(16):7-13.

[14] J.W.He,Y.W.Li.Analysis,design, and implementation of virtual impedance for power electronics interfaced distributed generation, J.IEEE Transactions on Industry Applications, 2011,47(6): 2525-2538.

[15] Tuladhar A, Jin H, Unger T. Control of parallel inverters in distributed ac power system with consideration of line impedance effect, J.IEEE Trans on Industrial Application,2000,36(1): 131-138. 